\title{
Orthodontic Treatment in the Rehabilitation of Congenitally Maxillary Lateral Incisors Agenesis with Multiple Maxillary Anterior Diastema
}

\author{
Bunga Fatimah and Ida Bagus Narmada \\ Department of Orthodontic, Faculty of Dental Medicine, Universitas Airlangga, Surabaya, Indonesia
}

\begin{abstract}
The maxillary lateral incisor is the second most common congenitally absent tooth. This is a case of a 25 -year-old with maxillary lateral incisors agenesis, multiple maxillary anterior diastema. Pre-adjusted technique was used, gingivectomy and frenectomy to release tooth movement. Patient's profile was straight, interdental relationship was class I, enlarged space of maxillary lateral incisors, space was replaced by prostheses. The treatment of maxillary lateral incisors agenesis responsible for orthodontic, periodontic and prosthodontic achieved a pleasant aesthetic and function.
\end{abstract}

Key Words: agenesis, pre adjusted technique, lateral incisors

\section{INTRODUCTION}

Tooth agenesis, one of the most common developmental dental anomalies in humans, is the congenital absence of one or more teeth. ${ }^{1,2}$ The reported incidence of permanent tooth agenesis varies from 1.6 to $9.6 \%$, excluding third molars, which occurs in $20 \%$ of the population. ${ }^{2,3}$ It usually affects maxillary lateral incisors, mandibular central and lateral incisors with the common missing teeth in Asian population being the mandibular incisors. ${ }^{4}$ Maxillary lateral incisors agenesis affects approximately $2 \%$ of the population. ${ }^{5}$ The maxillary lateral incisors agenesis has a great aesthetic and functional impact for the anomaly patient, as well as for health professionals, making the treatment plan a great challenge. ${ }^{6}$

Maxillary lateral incisors agenesis (MLIA) is the most common congenitally missing permanent tooth condition in the maxillary anterior region (esthetic zone). It has been found that females are more affected than males, ${ }^{5}$ and bilateral MLIA are more frequently reported than unilateral cases. ${ }^{7}$

The multiplicity of tooth agenesis theories suggests a multifactorial etiology that involves genetic regulation and environmental factors. ${ }^{8}$ Maxillary lateral incisors agenesis whether unilateral or bilateral may affect the self-esteem

Paper presented at the Joint Scientific Meeting in Special Care Dentistry, July 5, 2019, Amerta Room, 4th Floor, main campus of Universitas Airlangga, Surabaya, Indonesia.

Corresponding author: Ida Bagus Narmada

Department of Orthdontic

Faculty of Dental Medicine

Universitas Airlangga

Jl. Mayjen. Prof. Dr. Moestopo No. 47 Surabaya 60132 - Indonesia

Email: dr_narmada@yahoo.com and social relationships of the affected individual. Maxillary lateral incisors agenesis may cause a variety of esthetic and functional problems; their absence may cause a diastema between the central incisors, spacing between permanent incisor and canine, mesial migration of canines, midline shift in case of a unilateral missing tooth. ${ }^{5,9}$

The options available to the clinician are the possibility of space closure with mesial repositioning of canines, followed 
by teeth recontouring; or a combination of space opening and prosthetic replacement of the missing lateral tooth. ${ }^{7}$

Missing teeth are significant enough reasons for extensive oral rehabilitation requiring orthodontic, restorative and prosthodontic procedures at the dental clinic, as various combinations of poor aesthetics and occlusal dysfunction are presented by the patients. ${ }^{6,9}$

\section{CASE REPORT}

This is a case of a 25-year-old female with maxillary lateral incisors agenesis, multiple maxillary anterior diastema, maxillary central incisors protrusion and mandibular dental midline shift to the left by $2 \mathrm{~mm}$. Extraoral examination showed pleasing facial profile with competent lips. (Figure 1) Intraoral examination showed Angle's Class I molar relationship, $3 \mathrm{~mm}$ of overjet and overbite with absence of maxillary lateral incisors. (Figure 2) After radiographic examination (orthopantomogram), diagnosis of maxillary lateral incisors agenesis was made. (Figure 3) Intraoral examination of her mother also revealed the absence of maxillary lateral incisors which confirmed etiology of familial origin.

\section{Treatment Planning and Treatment Progress}

The treatment used pre adjusted technique with MBT 0.022 , the first steps progressed as alignment and leveling with $0.012,0.014,0.016 \mathrm{NiTi}$ followed by $0.016 \times 0.016$, $0.016 \times 0.022 \mathrm{NiTi}$ and $0.017 \times 0.025$ stainless steel for five months. (Figure 4) The second steps were frenectomy and gingivectomy of maxillary gingival to make the excellent movement of tooth, followed by maxillary central anterior diastema closure. (Figure 5). The third step was space preparation for maxillary lateral incisors by closing the maxillary central anterior diastema and distalization of maxillary canine using power chain and open coil spring $(0.010 " x 0.030 " \mathrm{NiTi})$. (Figure 6) Space preparation for maxillary lateral incisors and retraction of canine was done in six months. The fourth step was retraction of maxillary central incisors using sliding mechanics. The last step is arch compatibility.
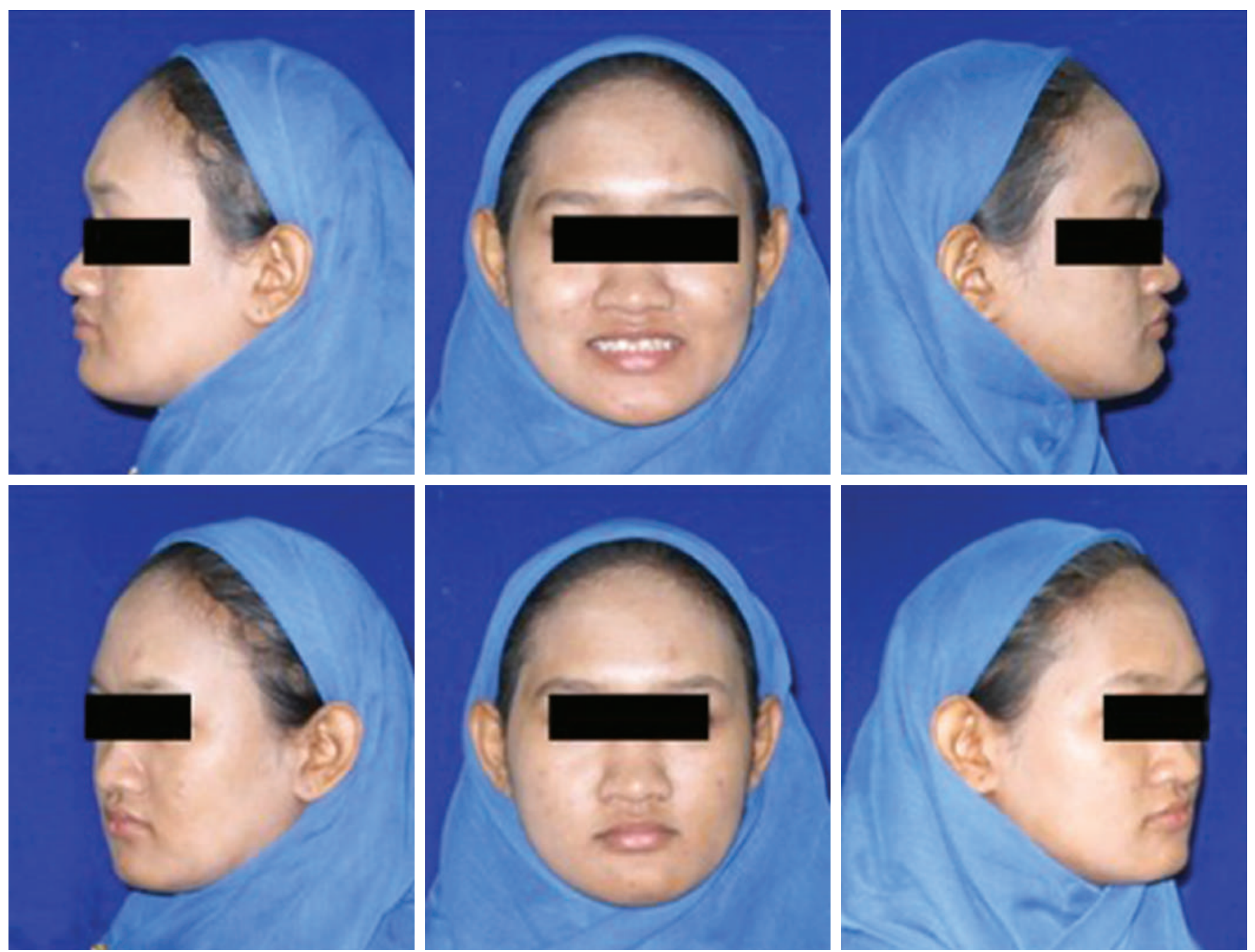

Figure 1. Extraoral facial profile pre-treatment. 

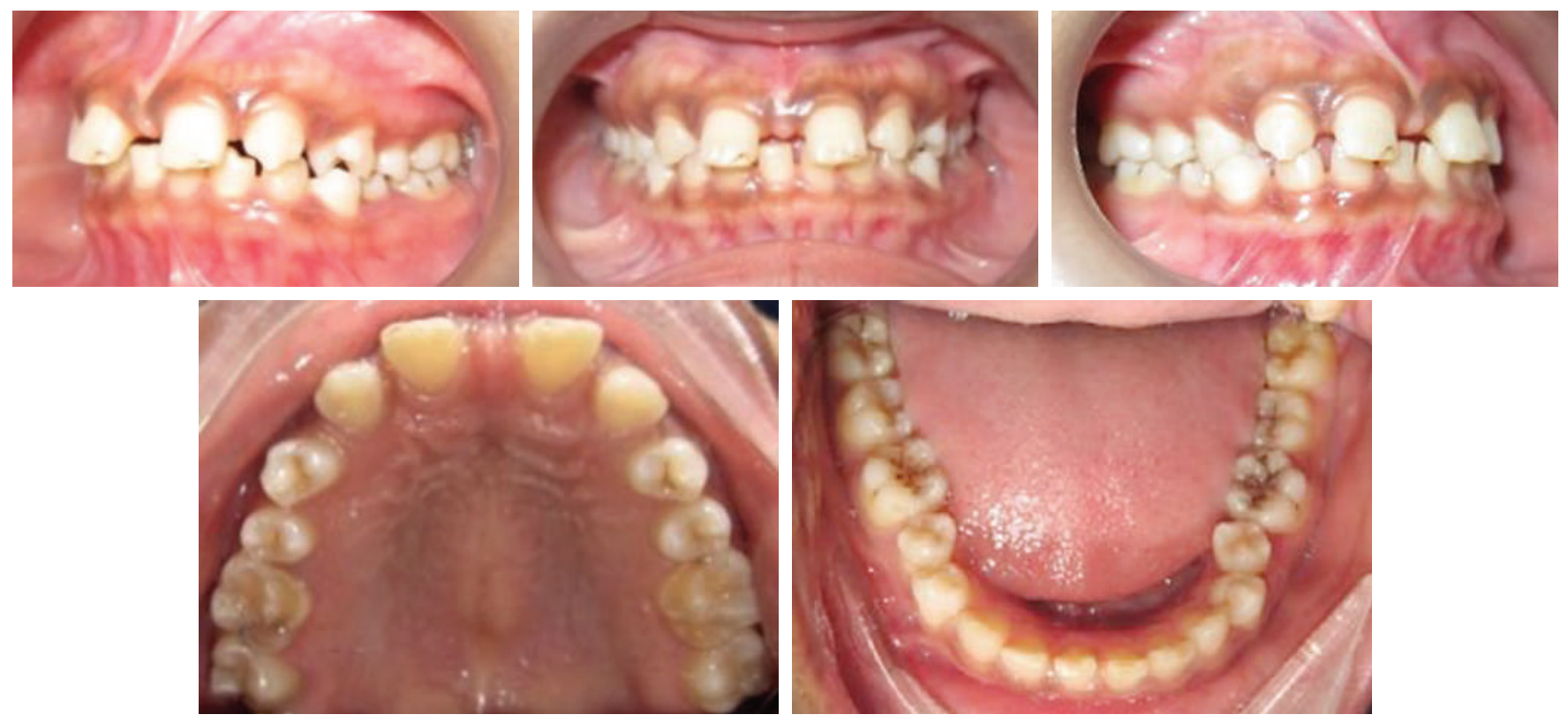

Figure 2. Intraoral pre-treatment.
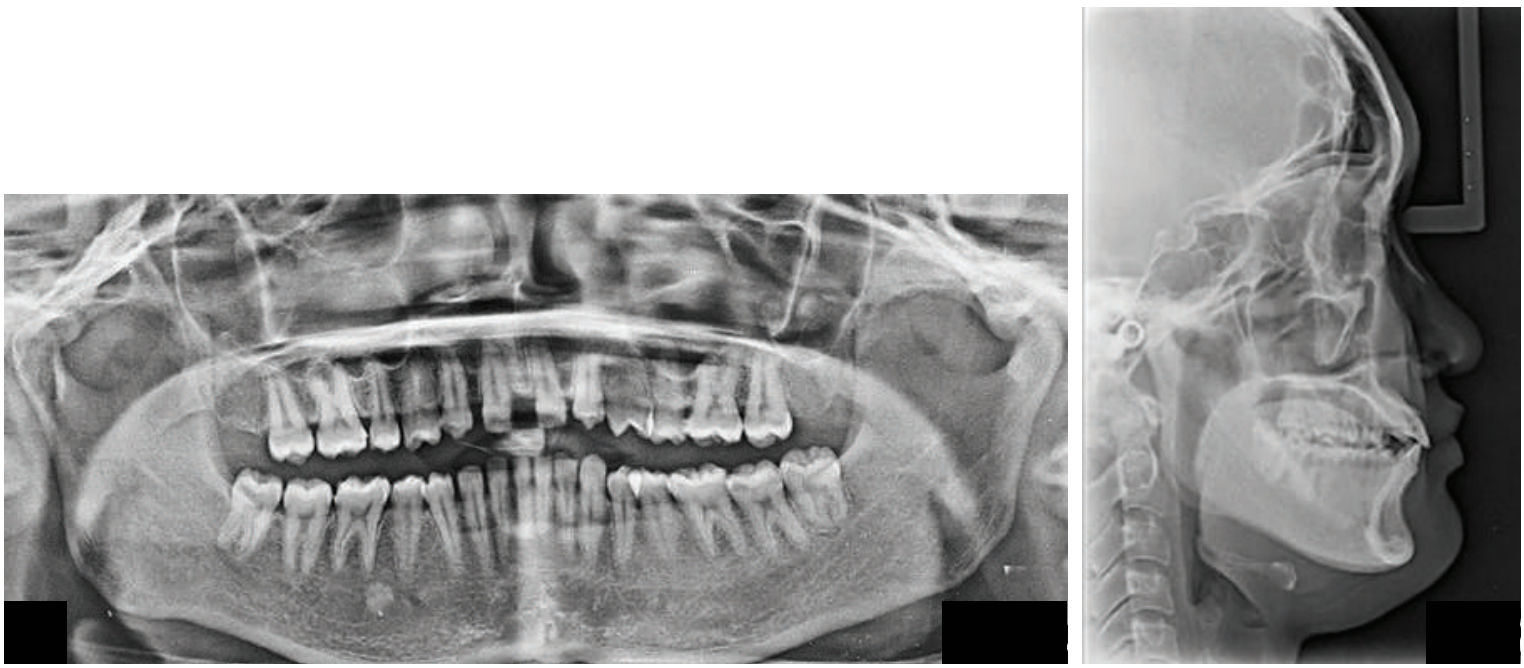

Figure 3. X-rays pre-treatment.

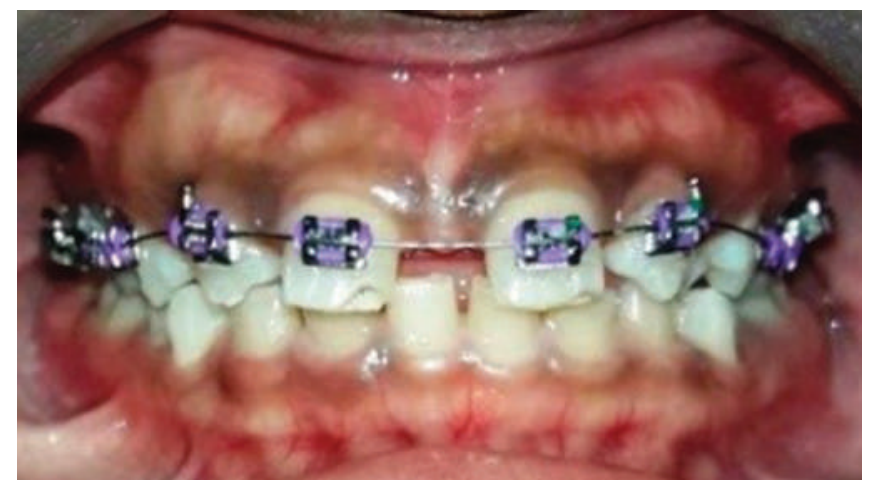

Figure 4. Leveling and aligning with NiTi before frenectomy and gingivectomy.

\section{Results of Orthodontic Treatment}

The patient was presented for 17 months by the orthodontist for the correction of maxillary lateral incisors agenesis. Maxillary central anterior diastema was closed, space for maxillary lateral incisors available, maxillary central incisors proclined was normal with no mandibular midline shift (Figure 7.1). Figure 7.2 showed satisfactory result of facial profile. A post-treatment radiographic examination (orthopantomogram) showed a good outcome of tooth paralleling (Figure 7.3). At the end of treatment, combined treatment of orthodontic and prostodontic was performed, the space of maxillary lateral incisors were replaced by prostheses (Figure 8). 

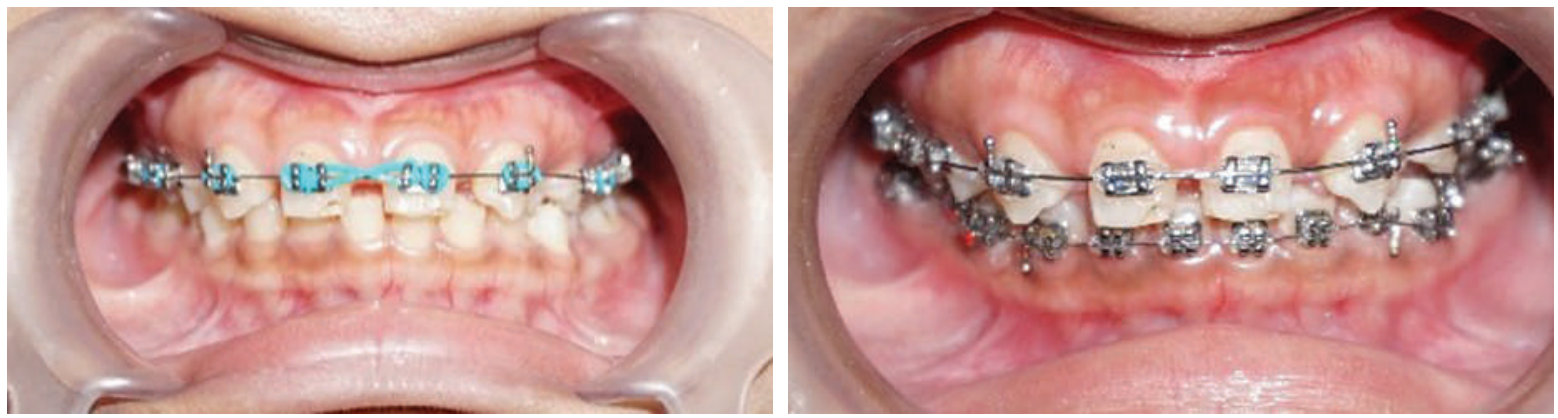

Figure 5. Space closure of maxillary central anterior.
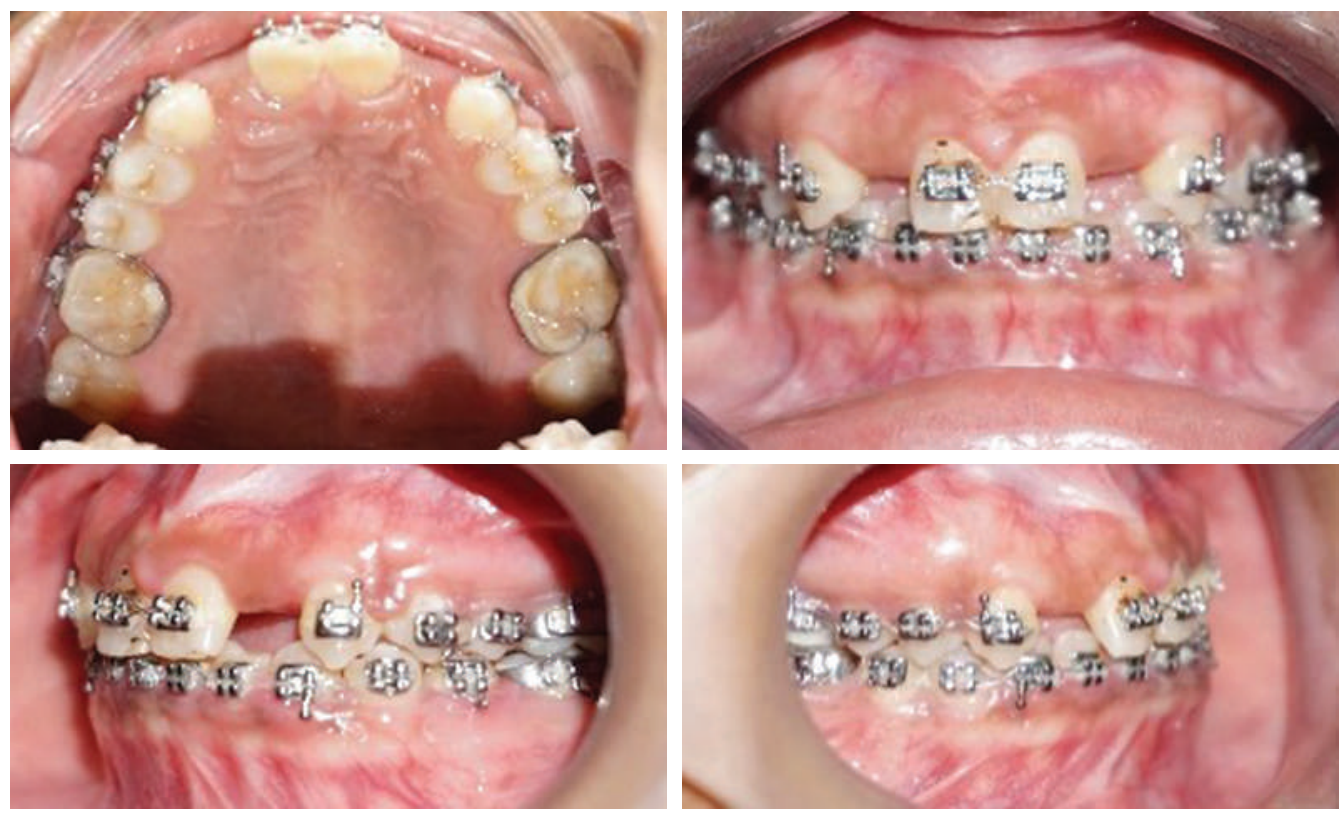

Figure 6. Maxillary canine distalization.
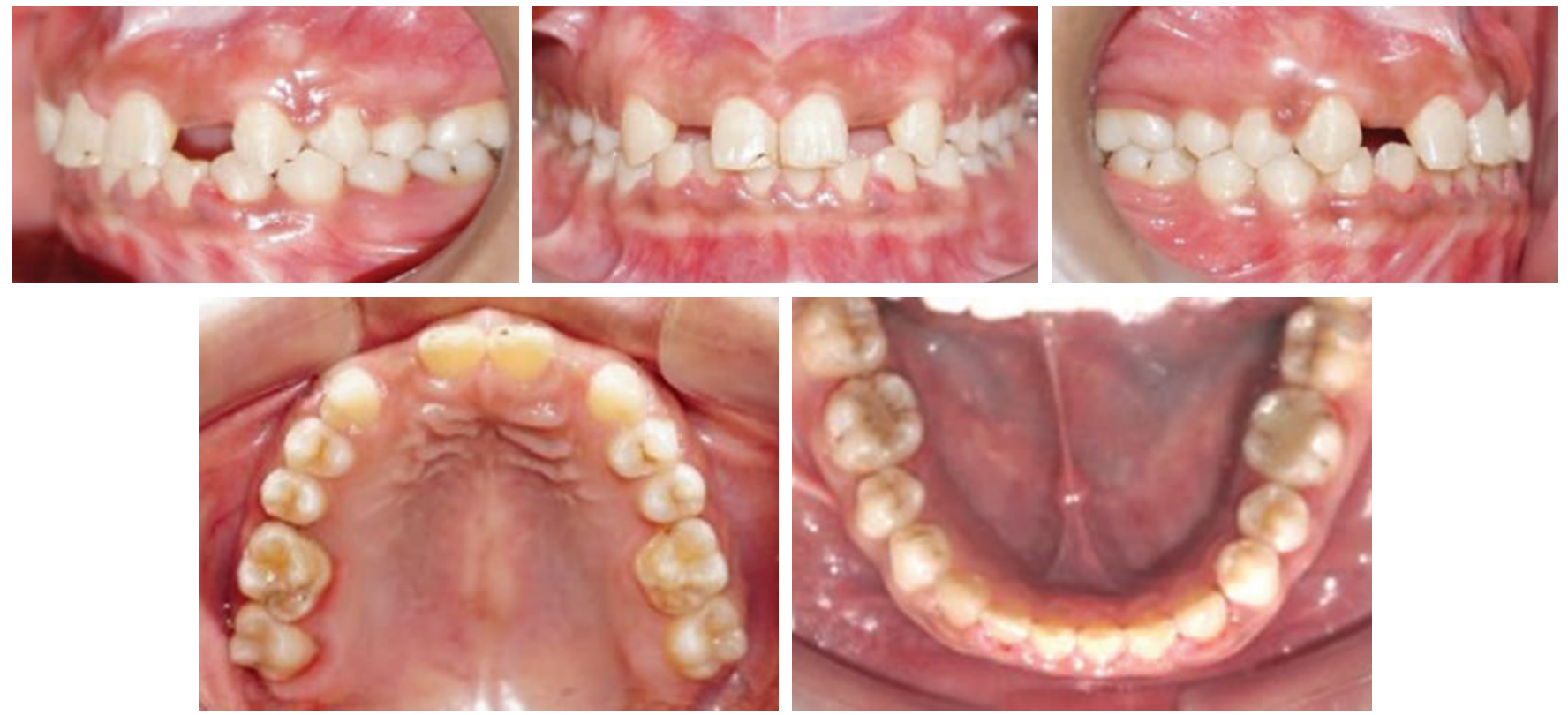

Figure 7.1. Intraoral post-treatment. 

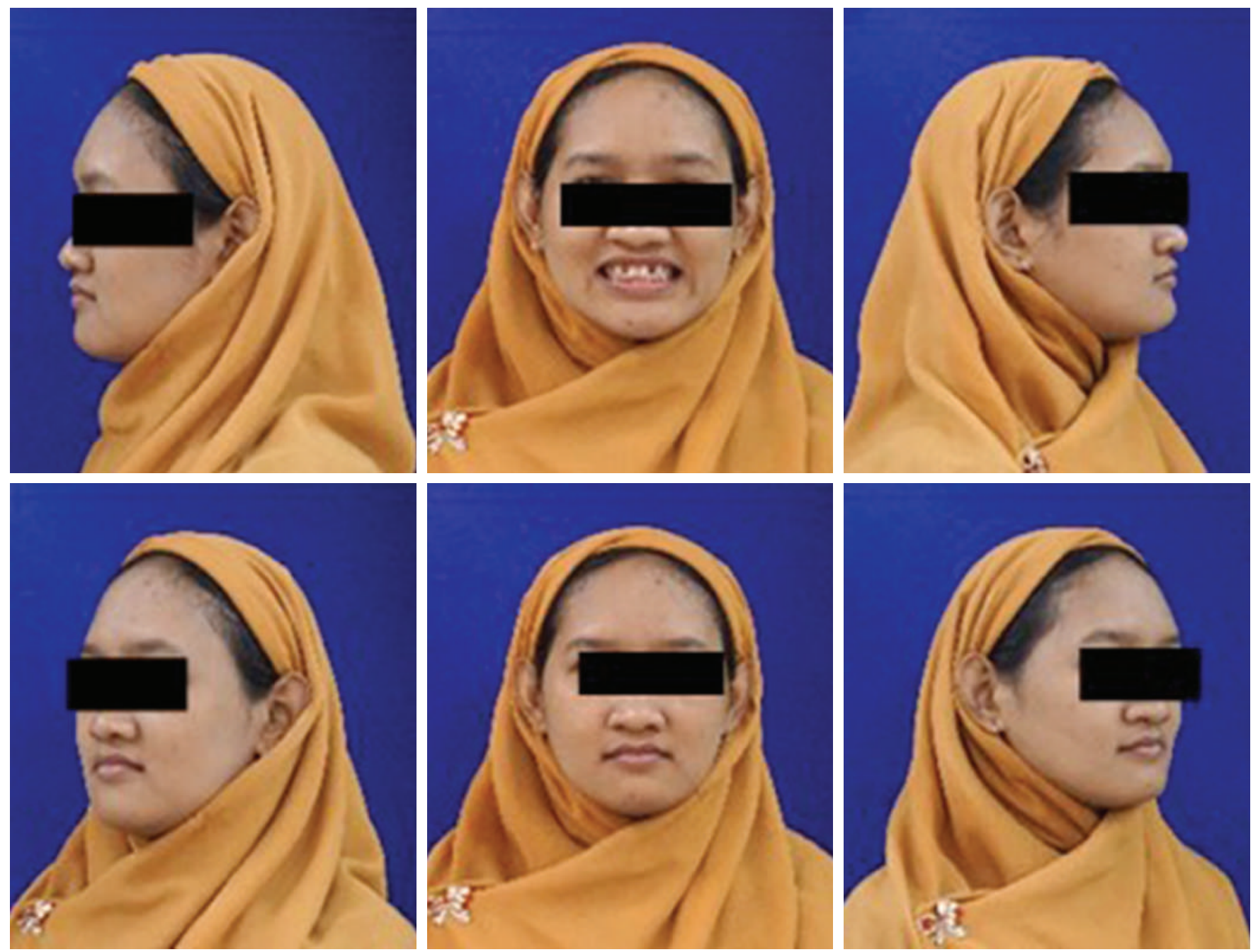

Figure 7.2. Extraoral facial profile post-treatment.
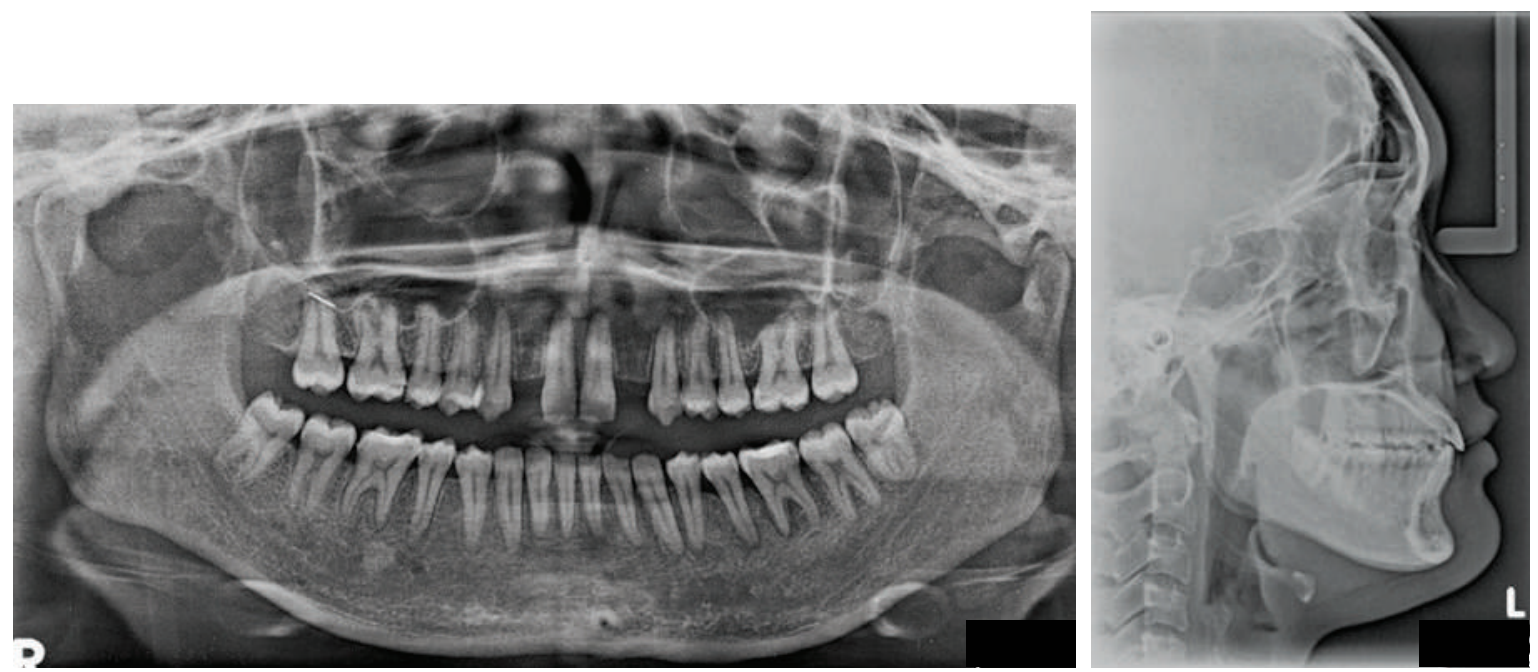

Figure 7.3. X-rays post-treatment. 

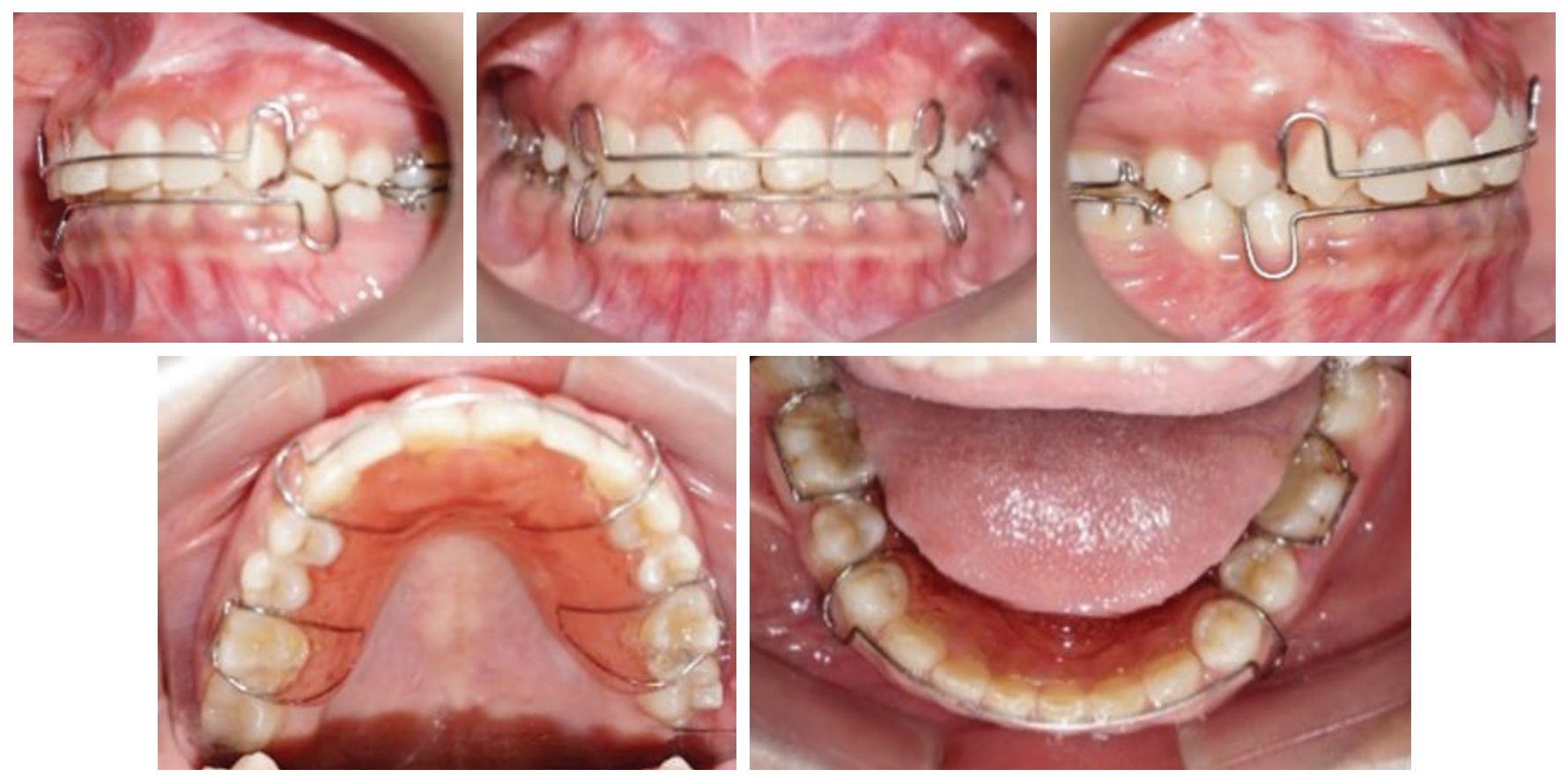

Figure 8. Hawley retainer with partial denture of maxillary lateral incisors.

\section{DISCUSSION}

This case is very interesting for several reasons: It reports maxillary lateral incisors agenesis with multiple maxillary anterior diastema. The objective of orthodontic therapy is to form a good occlusion relationship, improving the health of the periodontium, and enhance dental and facial esthetics. Periodontal health is an important factor in successful orthodontic tooth movement; this combined with light, consistent and controlled orthodontic force result in the regeneration of bone and allow the teeth to relocate through the alveolar bone. Appropriate forces are maintained to avoid necrosis which leads to undermining resorption. Therefore, it is mandatory to have good periodontal health not only before orthodontic treatment but also during and after orthodontic treatment. ${ }^{10}$ Abnormal frenum attachment results when a v-shaped bony cleft is formed between the two central incisors and a thick frenum resists orthodontic forces and is responsible for the relapse of space closure. In this case, the patient has an enlargement of maxillary anterior gingiva and abnormal frenum attachment (Figure 2). Frenectomy was done to make the excellent movement of tooth, followed by mesial space closing (Figure 5). The first line of treatment in the management of gingival enlargement is patient motivation to maintain oral hygiene. ${ }^{11}$ Gingivectomy also was done to improve the health of the periodontium and enhance the esthetics.

Treatment options of maxillary lateral incisors agenesis: 1) Canine substitution followed by space closure. 2) Space creation for maxillary lateral incisors agenesis followed by prosthetic replacement. ${ }^{7}$ Since the lateral incisors play a very important role in the smile's design, including the smile's arch, lip line and type I gingival height, management of missing maxillary lateral incisors requires thorough treatment planning and an interdisciplinary approach. Both treatment options have advantages and disadvantages. Space closure-canine substitution is usually indicated in cases with smaller, shorter, less angular canines having narrow mesiodistal widths at the cementoenamel junction, slight protrusive profile, cases requiring extraction in mandibular arch due to arch length discrepancy. ${ }^{12}$ Canines with darker shade and normal dimension limit substitution. Extensive remodeling of the teeth might involve such complications as the development of increased sensitivity to hot and cold, dental pain, tooth discoloration due to dentin exposure or pulp obliteration, and dental caries. ${ }^{12}$ Adult patients with retrusive profile with class I canine relations are better candidates for prosthetic replacement.

Treatment to be chosen depends on each case. In this case, maxillary lateral incisors agenesis occurs bilaterally. Etiology is unknown, with the possibility of hereditary factors. Analysis of space requirements concluded that this treatment was non-extracted and second treatment option was selected, so as not to compromise facial profile. Space was created by closing maxillary anterior diastema and distalization of canine, space was replaced by prostheses for maxillary lateral incisors.

Pre adjusted technique was used for the mechanic movement of tooth. Brackets with a predetermined angulation to guide tooth movement and prescriptions of pre adjusted brackets are widely used. ${ }^{13}$ By using pre adjusted technique, there is no need for wire bending. So, 
Table 1. Cephalometric analysis pre-treatment and post-treatment

\begin{tabular}{lll} 
Variable & Pre-treatment & Post-treatment \\
$<$ FH-MP & $29^{\circ}$ & $29^{\circ}$ \\
$<$ NAP & $-4^{\circ}$ & $-4^{\circ}$ \\
$<$ SNA & $85^{\circ}$ & $84^{\circ}$ \\
$<$ SNB & $83^{\circ}$ & $82^{\circ}$ \\
Wits Appraisal AO BO & -1 & -1 \\
$<$ l line NA & $32^{\circ}$ & $30^{\circ}$ \\
$<$ l lineNB & $29^{\circ}$ & $28^{\circ}$ \\
\hline Rickets Lip Analysis & Upper lips $4 \mathrm{~mm}$ behind the line & Upper lips $4 \mathrm{~mm}$ behind the line \\
& Lower lips 2 mm behind the line & Lower lips 2 mm behind the line \\
\hline Steiners Lip Analysis & Upper lips $1 \mathrm{~mm}$ behind the line & Upper lips $1 \mathrm{~mm}$ behind the line \\
& Lower lips $1 \mathrm{~mm}$ behind the line & Lower lips $1 \mathrm{~mm}$ behind the line \\
\hline
\end{tabular}

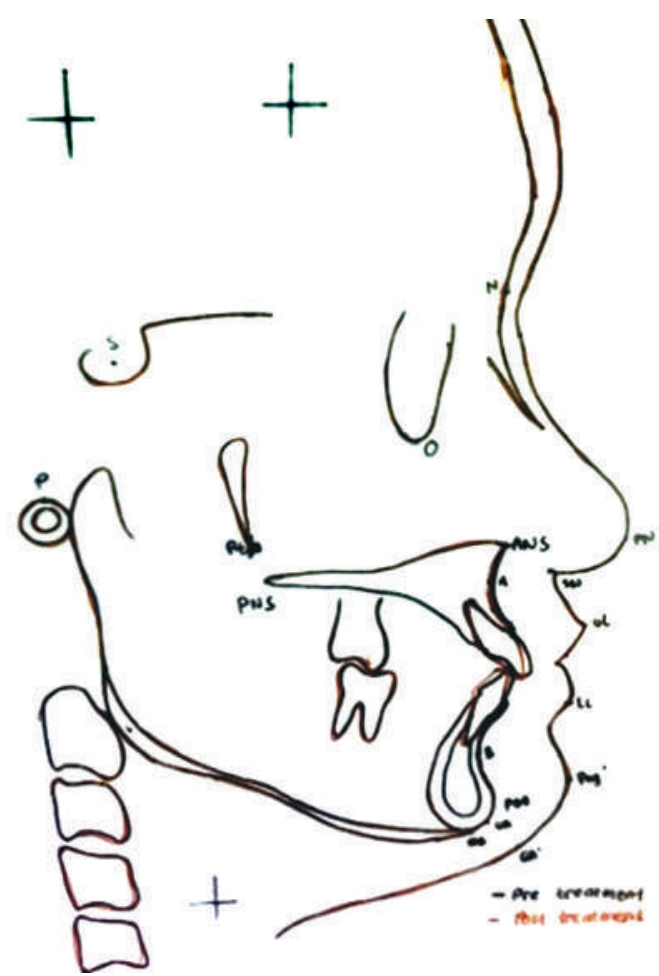

Figure 9. Superimpose of cephalometric pre-treatment (black) and post-treatment (orange).

patient will experience more comfort. Maxillary central incisors retraction was done due to the increased of incisal inclination (Table 1), normal profiles and normal inclination of lower incisors. The treatment plan was done by making discrepancy of dental set-up models, so the amount of space needed to replace maxillary lateral incisors in obtaining good function and aesthetics can be estimated. Treatment with more prosthetic use is mostly performed on adult patients. The choice does not have many advantages on posterior changes, especially in the case of the existing molar and canine's ideal relationship and cases of mild malocclusion. Care orthodontics also do not take a long time, but it takes time to improve form or replace prostheses during the process treatment and after completion of orthodontic treatment. ${ }^{10}$ The disadvantage of the use of prostheses is irritation to the gingiva compared with canine space closure and can sometimes deepen the pocket in the area of prostheses use. The prostheses were replaced with Hawley Retainer combined with partial denture for maxillary lateral incisors in the retainer phase during the last orthodontic treatment (Figure 8).

The amount of space needed to prepare the room for the prostheses is determined by two factors. The first is the aesthetic factor from the mesiodistal width of the anterior teeth. Relationship between the width of the central and lateral incisors must be considered according to the golden proportion of the width of one lateral incisor of $2 / 3$ central incisors. The second factor is occlusion, with obtaining an anteroposterior occlusion relationship a good buccal segment, canine tooth connection normal, coherent, and optimal midline, overbite, and overjet will provide the right room for placement of prostheses so it will obtain a good aesthetic appearance. ${ }^{14}$ It required $5 \mathrm{~mm}$ space of maxillary lateral incisors in this case.

Superimpose of cephalometric measurements showed that the inclination of central maxillary incisors became normal $\left(32^{\circ}\right.$ to $\left.30^{\circ}\right)$, with a more straight skeletal patient profile (SNA $85^{\circ}$ to $84^{\circ}, \mathrm{SNB} 83^{\circ}$ to $82^{\circ}$ ) which achieved an aesthetically and function pleasing result (Figure 9 ).

\section{CONCLUSION}

Maxillary lateral incisors agenesis is complex and involves a multidisciplinary approach. Formulating an appropriate treatment plan for each patient should be taken into consideration. Generally, the treatment of choice should be the least invasive option that satisfies the expected aesthetic and functional objectives. The combination of maxillary lateral incisors agenesis with multiple maxillary anterior diastema, in this case, is responsible for dental presentation for orthodontic, periodontic and prosthodontic reasons to achieve an aesthetically and function pleasing result. 


\section{Statement of Authorship}

All authors participated in data collection and analysis, and approved the final version submitted.

\section{Author Disclosure}

All authors declared no conflict of interest.

\section{Funding Source}

None.

\section{REFERENCES}

1. Ritwik P, Patterson KK. Diagnosis of tooth agenesis in childhood and risk for neoplasms in adulthood. Ochsner J. 2018; 18(4):345-50. doi: 10.31486/toj.18.0060.

2. Sharma VK, Kumar S, Yadav K, Chaturvedi TP. Agenesis of lateral incisors: treatment options and case report. Indian J Sci Res. 2018; 08(2):155-60.

3. Watted N, Borbély P, Watted A, Ghannam N, Azzaldeen A, Muhamad Abu-Hussein M. Multidisciplinary approach in the rehabilitation of congenitally missing lateral incisors: a new trend in daily practice. Oral Health Care. 2016; 1(1):1-8.

4. Nirmala SVSG, Gokhale N, Sivakumar N, Quadar MA. Agenesis of Multiple Primary Teeth and Its Rehabilitation: A Case Report. Int J Clin Pediatr Dent. 2013; 6(1):55-7.

5. Silveira GS, Mucha JN. Agenesis of maxillary lateral incisors: treatment involves much more than just canine guidance. Open Dent J. 2016; 10:19-27. doi: 10.2174/1874210601610010019.
6. Ifesanya JU, Temisanren OT, Jaiyeoba OO. A radiographic assessment of the prevalence and pattern of dental agenesis in a Nigerian population. African Journal of Oral Health. 2018;8(1):10-5.

7. Pini NIP, De Marchi LM, Pascotto RC. Congenitally missing maxillary lateral incisors: update on the functional and esthetic parameters of patients treated with implants or space closure and teeth recontouring. Open Dent J. 2014; 8:289-94.

8. Al-Ani AH, Antoun JS, Thomson WM, Merriman TR, Farella M. Hypodontia: an update on its etiology, classification, and clinical management. BioMed Res Int. 2017; 2017:9378325

9. Arandi NZ,Mustafa S. Maxillary lateral incisor agenesis; a retrospective cross-sectional study. Saudi Dental Journal. 2018; 30(2):155-60.

10. Janu A, Agarwal L, Singh K, Singh A. Periodontal procedures adjunct to orthodontic treatment. Orthodontic Journal of Nepal. 2015; 5(1):42-5.

11. Prabhu M, Ramesh A, Thomas B. Treatment of orthodontically induced gingival hyperplasia by diode laser - case report. NUJHS. 2015;5(2):66-8

12. Anandita R, Widayati R. Penatalaksanaan Kasus Maloklusi Dengan Agensis Insisif Lateral Atas Dan Premolar Dya Bawah Pada Periode Gigi Bercampur. Journal of Dentistry Indonesia. 2009; 16(1):18-24.

13. de Mendonca MR, Verri ACG, Fabre AF, Cuoghi OA. Analysis of mesiodistal angulations of preadjusted brackets. Braz Oral Res. 2014; 28(1):1-8.

14. Abu-Hussein M, Watted N, Abdulgani A, Kontoes N. Prosthodonticorthodontic treatment plan with two-unit cantilevered resin-bonded fixed partial denture. IOSR-JDMS. 2015; 14(12):131-6. 